University of Wollongong

Research Online

Faculty of Commerce - Papers (Archive)

Faculty of Business and Law

$1-1-2008$

\title{
The impact of knowledge management infrastructure on organisational competitiveness in a Confucian-socialist market economy
}

Thi Nguyet Q. Nguyen

Southern Cross University, cindyn@uow.edu.au

Philip A. Neck

Southern Cross University

Thanh Hai Nguyen

Monash University

Follow this and additional works at: https://ro.uow.edu.au/commpapers

Part of the Business Commons, and the Social and Behavioral Sciences Commons

\section{Recommended Citation}

Nguyen, Thi Nguyet Q.; Neck, Philip A.; and Nguyen, Thanh Hai: The impact of knowledge management infrastructure on organisational competitiveness in a Confucian-socialist market economy 2008, 551-556. https://ro.uow.edu.au/commpapers/1430 


\title{
The impact of knowledge management infrastructure on organisational competitiveness in a Confucian-socialist market economy
}

\begin{abstract}
The critical role of knowledge management (KM) in achieving and sustaining a competitive advantage (CA) has been strongly emphasised in the extant literature. However, most previous studies were conceptually grounded and empirically examined in advanced, developed and newly industrialised countries and from a large company perspective. Meanwhile, little attempt has been made to address the relative importance of different factors constituting the organisational KM infrastructure capability in the context of Asian emerging, less developed countries such as Vietnam where a socialist market economy, a Confucian culture and a majority of small and medium sized enterprises currently exist. By adopting a resource-based theory of the firm with an extension of a knowledge-based perspective, this paper aims at developing and empirically validating a conceptual model of the relationships between KM infrastructure capability components and their impacts on a firmpsilas CA in Vietnam. The results of 148 surveyed respondents in the construction industry reconfirmed a general agreement found in the literature that a combined social and technological approach is ideal to take advantage of their significant positive correlations in improving organisational competitiveness. Moreover, in the Vietnamese-specific context, the study indicated that while culture is the most important issue affecting $\mathrm{KM}$, integration with information technology may assist to overcome cultural barriers and provide a stronger contribution to a firmpsilas CA.
\end{abstract}

\section{Keywords}

impact, knowledge, management, infrastructure, organisational, competitiveness, Confucian, socialist, market, economy

\section{Disciplines}

Business | Social and Behavioral Sciences

\section{Publication Details}

Nguyen, T. Q., Neck, P. A. \& Nguyen, T. (2008). The impact of knowledge management infrastructure on organisational competitiveness in a Confucian-socialist market economy. Proceedings of The 5th International Conference on Service Systems and Service Management (pp. 1-6). Melbourne, Australia: IEEE. 


\title{
The impact of knowledge management infrastructure on organisational competitiveness in a Confucian-socialist market economy
}

\author{
Thi Nguyet Que Nguyen, Dr. Philip A. Neck, Thanh Hai Nguyen
}

\begin{abstract}
The critical role of knowledge management (KM) in achieving and sustaining a competitive advantage (CA) has been strongly emphasised in the extant literature. However, most previous studies were conceptually grounded and empirically examined in advanced, developed and newly industrialised countries and from a large company perspective. Meanwhile, little attempt has been made to address the relative importance of different factors constituting the organisational KM infrastructure capability in the context of Asian emerging, less developed countries such as Vietnam where a socialist market economy, a Confucian culture and a majority of small and medium sized enterprises currently exist. By adopting a resourcebased theory of the firm with an extension of a knowledge-based perspective, this paper aims at developing and empirically validating a conceptual model of the relationships between $\mathrm{KM}$ infrastructure capability components and their impacts on a firm's CA in Vietnam. The results of 148 surveyed respondents in the construction industry reconfirmed a general agreement found in the literature that a combined social and technological approach is ideal to take advantage of their significant positive correlations in improving organisational competitiveness. Moreover, in the Vietnamese-specific context, the study indicated that while culture is the most important issue affecting $\mathrm{KM}$, integration with information technology may assist to overcome cultural barriers and provide a stronger contribution to a firm's CA.
\end{abstract}

Index Terms - knowledge management infrastructure, social capability, technical capability, resource-based view, knowledgebased view, competitive advantage.

\section{INTRODUCTION}

IN the twenty first century landscape with all its uncertainty and dynamism, the foundation of organisational competitiveness has shifted from an emphasis on physical and tangible resources to knowledge (Wong and Aspinwall, 2005) and as such, managing knowledge-based resources has become the key for sustaining competitive advantage (CA) and superior performance (Grant, 1996b; Grover and Davenport, 2001; Jackson, Hitt, and DeNisi, 2003; Sharkie, 2003; and Teece, Pisano, and Shuen, 1997).

This study investigates the inter-relationships among KM infrastructure capability components and their impacts on a

Que Thi Nguyet Nguyen and Dr. Philip A. Neck are with the Graduate College of Management, Southern Cross University, Australia (email: t.nguyen.15@scu.edu.au \& philip.neck@scu.edu.au)

Thanh Hai Nguyen is with the Department of Management, Monash University, Australia (email: Thanh.Nguyen@buseco.monash.edu.au) firm's CA through a survey conducted in Vietnamese construction industry. Viewed from both social and technical perspectives, the study also aims at predicting which components of KM infrastructure would be most significant and effective in the context of Vietnam, one of the Asian developing countries with its own specific features, characteristics and conditions.

The paper begins with an overview of the RBV of KM coupled with a review of empirical studies that describe and link KM infrastructure capability components leading to positive outcomes. Drawing on the literature review and the theoretical issues discussed, a specific model of $\mathrm{KM}$ infrastructure capability-based CA of the firm is proposed. The next section presents an outline of the methodology employed for conducting the survey and its findings based on various statistical analyses. The paper concludes with an interpretation and discussion of the overall results gained from the study, followed by some indications of the study limitations as well as the proposed future research directions.

The key implication in using this model is that practising managers in Vietnam and other Asian developing countries with similar economic and Confucian cultural environments, while employing both social and technical KM capabilities, need to strongly emphasise the more important role of cultural elements to achieve and sustain a CA in the current complex landscape.

\section{LITERATURE REVIEW}

This section deals respectively with a RBV of KM and a review of KM infrastructure capability.

\subsection{Resource-based view of knowledge management}

The RBV of the firm examines the link between a firm's idiosyncratic attributes and performance (Barney, 1991) based on its internal strengths to take advantage of opportunities and counter threats in the market, aimed at creating sustainable CA through acquiring, utilising, and exploiting firm-specific resources (April, 2002; Riahi-Belkaoui, 2003) and, more importantly, integrating different resources to form strong organisational capabilities (Grant, 1996a; Verona, and Ravasi, 2003; and Zollo and Winter, 2002). Emerging as an extension of the RBV, the knowledge-based perspective defines firms as bodies that generate, integrate and distribute knowledge (McEvily, and Chakravarthy, 2002; Miller, 2002; Narasimha, 2000; and Narasimha, 2001) which is considered to be the key or strategic asset to hold the potential of sustainable CA (Grant, 1996a; and Lopez, 2005).

Thus, adopting the resource-based theory of the firm blended with a knowledge-based approach, KM capability is explicitly recognised to be central in creating CA of a firm in today's 
dynamic market place. The following section provides a review of empirical studies dealing with this concept.

\subsection{Review of KM infrastructure capability}

Viewed from resource-based and knowledge-based perspectives, Gold, Malhotra, and Segars (2001), followed by Smith (2006) are amongst the first KM researchers to identify that technology, culture, and structure are rare and firmspecific resources which likely serve as the source of organisational capability. Meanwhile, Lee and Choi (2003) measure the impact of $\mathrm{KM}$ enablers including structure, culture, people, and technology on organisational performance. Similarly, Khalifa and Liu (2003), Gimenez and Rincon (2003), and Zheng (2005) identify a number of factors as the primary sources of organisational effectiveness that include strategy, culture, structure, leadership, and technology.

It is noted that Chuang's (2004) model is one of a limited number of studies employing the RBV of KM to develop theoretical links and empirically examine the relationship between KM infrastructure capability and CA. However, the model examined the four elements of KM resources of a firm in isolation (namely structure, culture, and people as the social perspective, and information technology as the technical perspective) which is inconsistent with extensive discussions found in the literature of the interwoven nature among the organisational factors (Zheng, 2005). In addition, most studies were conceptually grounded and empirically examined in advanced, developed and newly industrialised countries with a heavy focus on large companies. To date, only scant attention has been paid to address the relative importance of different factors constituting the organisational $\mathrm{KM}$ infrastructure capability in the context of Asian emerging, less developed countries considering their own specific features, characteristics and conditions.

This paper seeks to fill the identified gaps by adapting Chuang's (2004), Lee and Choi (2003), and Smith's (2006) studies to develop a theoretical model of KM infrastructure capability based CA of the firm and then, empirically to test the model by conducting a survey in Vietnam where a socialist market economy, a Confucian culture and a majority of SMEs currently exist. The development of the research model is discussed in the following section.

\section{THEORETICAL DEVELOPMENT}

This section discusses the technical and social KM capabilities and CA and continues to propose a research model.

\subsection{Technical KM capability and CA}

Though described as a major business resource and a key source for attaining long-term CA (Gold et al., 2001; Nemati, 2002), little evidence has been found of the direct effects of IT alone and performance correlations while at the same time, if existing (though not significant), frequent negative correlations suggest that IT may worsen a firm's competitive position (Porter, 1985; and Powell and Dent-Micallef, 1997). Due to possible IT imitation by competitors, IT per se does not generate sustainable performance advantages and firms must use IT to leverage or exploit other firm-specific, intangible resources such as organisational leadership, culture, and business processes (Clemons and Row, 1991; and Henderson and Venatraman, 1993). Citing the theory of technology assimilation, Khalifa and Liu (2003) also state that technologies must be infused and diffused into business processes to enhance organisational performance (Cooper and Zmud, 1990; and Fichman and Kemerer, 1997). In the context of KM, therefore, IT should be incorporated with other KM capability dimensions to exhibit and significantly improve its impact on a firm's CA.

\subsection{Social KM capability and CA}

Organisational social resources generally comprise the sum of the actual and potential resources available that derive from the network of relationships possessed by a human or in a social unit (Nahapiet and Ghoshal, 1998). Lee and Choi (2003) propose that the ability of organisational structure, organisational culture, and people as the three critical dimensions of social KM resources to encourage the multifaceted activities associated with successful implementation of $\mathrm{KM}$ has been found to be a key distinguishing factor of successful firms. These valuable resources typically evolve over a long period of time through the accumulation of organisational operation experience (Gold et al., 2001), and thus, become hard to acquire and complex to duplicate. When effectively combined with the strong technical KM dimension they will become a unique organisational KM infrastructure capability which provides a sustained CA (Chuang, 2004).

\subsection{Proposed research model}

Based on findings in the literature review coupled with theoretical development, a research model of KM infrastructure capability-based CA of the firm is now proposed (Figure 1). The key components are identified as the technical KM capability (IT) and the social KM capability contributing to organisational CA. The model demonstrates that these two perspectives of KM infrastructure capability have inter-correlations which strongly support their impacts on CA.

\section{Figure 1: Theoretical Model}

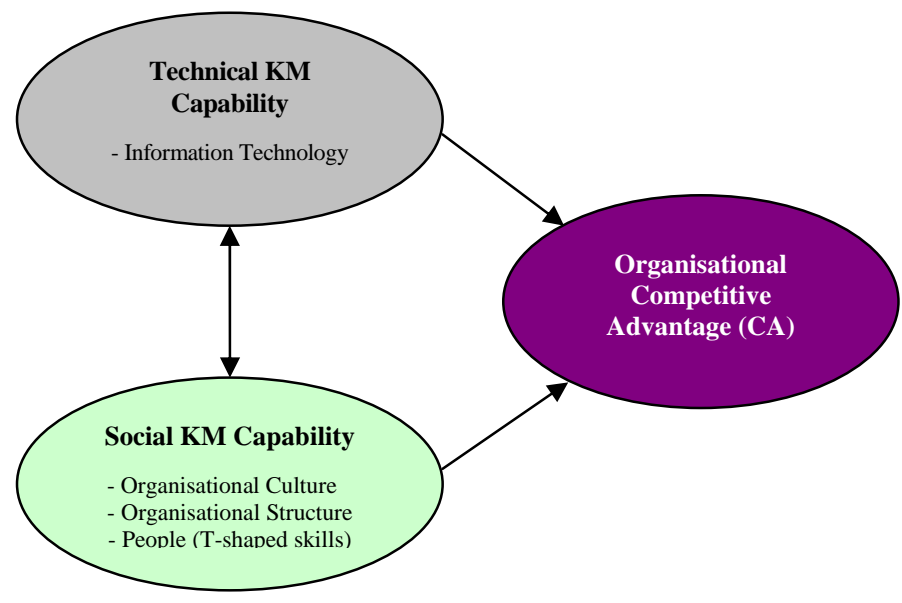




\section{METHODOLOGY}

This section deals with developing measures of theoretical constructs and techniques of data collection in this study.

\subsection{Operationalising measures}

There are three main constructs in the theoretical model, namely (1) technical KM capability; (2) social KM capability; and (3) competitive advantage.

(1) Technical KM capability or IT is measured based on Smith's (2006) instrument scale reflecting numerous aspects of technological infrastructure that are part of effective KM within an organisation such as collaboration, distributed learning, and knowledge mapping.

(2) Social KM capability is predicted by the three-factor scales of organisational structure, culture, and people. The operationalisation of two variables, structure and culture, is adapted from Smith's (2006) study while the measures of human resource (or T-shaped skills) construct is developed by Lee and Choi (2003).

(3) Competitive advantage is a multi-dimensional construct adapted from Chuang's (2004) study including innovativeness, market position, mass customisation, and difficulty in duplicating.

\subsection{Data collection}

The survey questionnaires attached with invitation letters were directly distributed to 600 potential respondents as senior management participating in a large exhibition of construction firms (VinaBuild) organised in Hochiminh City, Vietnam in September 2007.

The reason for selecting this sector to gather empirical data is because it is a project-based industry which utilises a variety of many separate firms in a temporary multidisciplinary organisation and thus operates within a dynamic and changing environment (Kamara, Augenbroe, Anumba, and Carrillo, 2002). Effective $\mathrm{KM}$ is being recognised as a vehicle through which the industry can address its critical needs for innovation, enhanced business performance, client satisfaction, improved efficiency, and effectiveness (Egan, 1998; Egbu, Sturgesand, and Bates, 1999). As such, it is critical to identify on which factors to focus if construction firms are to improve their CA through effective management of their knowledge assets.

\section{DATA ANALYSIS AND RESULTS}

This section covers sampling procedures and the statistical analyses employed.

\subsection{Sample characteristics and profile}

A total of 170 responses were returned, 22 had data missing and, therefore, were not included in the analysis, producing an acceptable useable response rate of $25 \%$. A majority of the respondents obtained at least a bachelor's degree (80\%), had been working at their current company from 3-5 years (neary $40 \%$ ) as senior management. Most surveyed organisations were small and medium in size employing less than 300 employees (90\%) and originated from State-own enterprises (SOEs) with $34 \%$ as joint stock or joint venture, $22 \%$ as SOEs while only $37 \%$ were private companies.

5.2 Reliability and validity analysis
The construct validity and reliability of the multi-item constructs were assessed using the principle component analysis (PCA) with Varimax rotation and coefficient (Cronbach) alpha. Items with low factor loadings (absolute values below 0.5 ) were deleted, while values of coefficient alpha above 0.7 were considered to represent acceptable reliability (Hair, Anderson, Tatham, and Black, 1998).

Based on these criteria, the results of the study showed that all construct measurement scales had satisfactory coefficient (Cronbach) alpha (though slightly lower for IT construct). The PCA for all composite variables except organisational culture and people extracted only one underlying component with an eigenvalue greater than 1 explaining from $46.15 \%$ to $61.23 \%$ of the total variance in the original sets of variables and so unidimensionality was assumed. Moreover, all relevant items were found to have component loadings greater than the minimum criterion of 0.5 , therefore, these were considered to be acceptable for further analyses.

However, the two constructs (organisational culture and people) were both found to load into two components. To improve their validity and reliability, it was decided to recalculate these two variables using only those items correlated with the first of the underlying components which were then found to have acceptable levels of reliability and, thus, were used in all subsequent analyses.

\subsection{Pearson correlation analysis}

The results of Pearson product-moment correlations show significant positive correlations between all different components of KM infrastructure capability, namely culture, structure, people, and IT. In addition, each of these factors was also found to be significantly correlated with CA ( $\mathrm{p}<$ 0.01).

\subsection{Multiple linear regression analysis}

A standard multiple regression was performed between CA as the dependent variable and structure, culture, people, and IT as independent variables. The multiple correlation coefficient $(\mathrm{R}=0.58)$ was significantly different from zero, $\mathrm{F}$ $(4,105)=13.002, p<0.05$, and $30.6 \%$ of the variation in the dependent variable was explained by the set of independent variables (adjusted $\mathrm{R}^{2}=0.306$ ). Both culture, $\mathrm{sr}_{\mathrm{i}}^{2}=0.10, \mathrm{t}=$ 4.04, $\mathrm{p}<0.05$ and IT, $\mathrm{sr}_{\mathrm{i}}{ }^{2}=0.03, \mathrm{t}=2.11, \mathrm{p}<0.05$ were found to contribute significantly and uniquely to predicting CA while structure and people were found not to provide any significant unique contribution to prediction $(\mathrm{t}=0.89$ and 0.28 respectively, $\mathrm{p}>0.05$ ).

\section{FINDINGS AND DISCUSSION}

It is stated that the Vietnamese cultural, economic, and political context shapes entrepreneurial business activities and strongly impacts a firm's ability to achieve CA and business success (Swierczek and Ha, 2003; Nguyen, Alam, and Perry, 2007a; Nguyen and Alam, 2007b). Within the scope of this paper, however, focus is directed to examining the internal environment of organisations. This is considered the paper's limitation that will be dealt with in further research. Given that the organisational structure, organizational culture, people, and IT were proposed as potential moderators of the 
conceptual model, the results of our study reveal that only two factors, namely cultural and technical KM capabilities, have unique and significant influences on a firm's CA. The following empirical evidence from Vietnamese context-based literature supports the findings and explains why this could be the case.

\subsection{Organizational culture}

One of the key findings of this study is that cultural KM capability makes a unique and significant contribution to a firm's CA. This is quite consistent with the study of Swierczek and Ha (2003) that cultural elements have a strong impact on Vietnamese business innovation and business activities. This argument is further supported by a number of studies showing that potential for entrepreneurial activities and business success can be enhanced by cultural factors in general and organizational culture in particular (Baughn, Cao, Le, Lim, and Neupert, 2006; Deshpande, Farley, and Bowman, 2004).

More specifically, the study of Le, Rowley, Truong, and Warner (2007), attempts to explain why cultural factors are critical to business success in Vietnam. Citing from Mcleod and Dieu (2001) they argue that 'Vietnam has had long exposure to Western values since the French colonization in the 1880s up to the 1950s and the US intervention until 1975' (p114). In addition, more than half the Vietnamese population were born after the Vietnam War who tend to be increasingly influenced by Western values and lifestyles. According to Le et al., (2007), this imprint may sustain a promising potential implication of western-based managerial practices with a selective approach.

Historically, Vietnam has also been strongly affected by Chinese Confucian culture. Though there are many debates on the contradictory roles between Neo Confucianism and Communism, their inter-relationship is recognised as a key distinct feature of business environment in Vietnam. These factors have shaped the organisational culture and can be considered a referencing system that prescribes ethical ways of doing business.

To many young Vietnamese, Confucian culture is values and beliefs while Western lifestyles and management approach are ideal. Given that $49.7 \%$ of business owners in Vietnam are young with an average age below 39 years (Pham, 2002), it may imply that Vietnamese entrepreneurs are getting younger and higher educated (79\% undergraduate and postgraduate in our study). They are more flexible and willing to change to enhance organisational CA.

It is clear that to improve innovation and competitiveness, Vietnamese enterprises need to incorporate Confucian philosophy, socialist market philosophy and a careful adaptation of new managerial approaches and innovative ideas in accordance with their 'belief reference system' (Mcleod and Dieu, 2001). Cultural factors can positively, or negatively, affect the entrepreneurs' willingness to take risks and make business decisions, while the presence of a risk avoidance attitude would be still prominent if an entrepreneurial culture was not strong (Nguyen et al., 2007a). These explain why the Vietnamese-specific cultural attributes are extremely important to entrepreneurial culture which, in turn, positively influences the KM capability of an organisation and its CA.

\subsection{Organizational structure}

Although positively and significantly correlated with other organisational factors such as culture, IT, people, and CA, organizational structure does not uniquely and significantly contribute to a firm's CA. This result of the study is supported by Deshpande et al., (2004, p22) claiming that 'Vietnamese firms emerging from central planning to some form of market socialism tend to be bureaucratic'. It means that they tend to focus on loyalty, commitment, regulations and formal organizational structure rather than on future orientation. The result is further supported by Berrell, Wright, and Hoa (1999) who state that due to strong influence by Confucian culture, in comparison to their Australian counterparts, Vietnamese managers were more accepting of hierarchical and formal management structures, placing less emphasis on individual actions and achievement, and being less willing to accept changes.

It is also widely recognised by many Asian and Vietnamese scholars that the adopted Western based managerial practices should be different from the original models due to different business and culture conditions. In addition, they must be implemented gradually and, thus, can limit an organisation's flexibility. As such, this explains why organisational structure, though positively correlated with other factors, may depend heavily on other social KM dimensions and does not give any unique and significant contribution to a firm's CA.

\subsection{Human resources}

King-Kauanui, Su, and Ashley-Cotleur (2006) indicate that Vietnamese human resource management practices rely more heavily on human labour factor than is found elsewhere. The scholars also acknowledge the importance of culture in forming organizational norms and practices which greatly emphasise collectivism and commitment.

However, contrary to this argument and other scholars' expectations, these current findings show that human KM capability does not contribute uniquely significantly to the prediction of a firm's CA. According to Tuan and Napier (2000) although emphasising collectivism, Vietnamese may not necessarily work as effective teams as generally expected because of a lack of common well-defined goals in group work while encouraging an increasing popularity of pursuing their personal goals.

As presented above, human KM capability is found to be positively correlated with other KM capability components and, thus, may depend on them, which supports the findings of this study and explains why no significant contribution of human KM resource to organisational CA was found.

\subsection{Information technology}

According to Le (2006), Vietnamese entrepreneurs' demands for technological innovation are relatively low. The average expenditure of Vietnamese SMEs for this purpose accounts for only $0.2-0.3 \%$ of total revenue in comparison with $5 \%$ for Indian SMEs or $10 \%$ for Korean SMEs. This figure indicates that SMEs are not proving to be able to upgrade their technology and equipment to high levels of technological development.

As found recently by Nguyen et al., (2007a), although facing an urgent need for technological innovation and CA 
improvement, many private firms in Vietnam do not have the capability to adopt new technology due to an inadequate labour force, inadequate capital and managerial skills. Most private SMEs' equipment and production facilities are based on traditional technologies operated under manual or semiautomatic control or transferred from SOEs as well as other domestic sources which are already out of date by two to three or even four technological generations in comparison with regional countries and even with larger Vietnamese companies in the same industry.

The construction industry in Vietnam, though representing by $90 \%$ as SMEs (less than 300 employees) as the result of this study, has experienced several distinct characteristics such as a high demand in technology and a fast-speed development to meet ever increasing infrastructure needs and requirements. Moreover, a major part of the industry originated from SOEs (41\% as joint stock, joint venture, or fully owned by foreigners, $22 \%$ SOEs, and only $37 \%$ private companies) who are eligible to the State's policies such as special credit loans, tax incentives, training assistance, support in importing equipment and transferring technologies. They also receive more preferential support from their own governing body and get easier access to resources than private SMEs (Nguyen et al., 2007a). These specific industrial characteristics, plus the emerging private business sector and the fast growing economic boom, have created a more intensive and dynamic competition landscape, requiring firms to upgrade their technological equipment and information systems to acquire and maintain a CA. As a result, the technical KM capability positively and significantly influences the firms' CA.

\subsection{Conclusion}

This research has developed, operationalised, and empirically validated a theoretical model that explains the inter-relationships amongst KM infrastructure elements and their role in achieving CA in Vietnam, an emerging Asian, less developed country where a Confucian culture, a socialist market economy and a majority of SMEs exist. A survey study of 148 senior executives in the construction industry provides strong support for the research model proposed. Consistent with general agreement in the literature that a combined social and technological approach is ideal, it is contended that there are significant positive correlations amongst the KM infrastructure capability components as well as between them and organisational CA. However, the findings show that, in the current Vietnamese-specific environment, only two critical factors of cultural and technological KM dimensions make a unique significant contribution to a firm's CA with culture having a major influence. This result highlights the necessity to consider culture as a dominant issue in KM to enhance organisational outcomes.

In terms of practical implications, the paper attempts to provide Vietnamese business executives, especially those from SMEs in the construction industry, with a better understanding about how firms need to be effectively managed to improve their overall KM infrastructure capability to leverage, exploit, and sustain a CA. In addition to consider a combination of technical and social KM resources, practising managers should investigate and take full advantages of IT in relation to other key organisational factors to overcome cultural barriers and strengthen their contribution to long-term performance.

The limitations suggest that further research needs to be conducted in other sectors to provide a more comprehensive picture of KM in Vietnam. Moreover, an external business environment, especially involving cultural issues, also needs to be investigated systematically to link organisational resources. Finally, analysis of knowledge management from a processoriented perspective and the relationships between KM infrastructure and process capabilities would be the next step of development for firms to move towards a more proactive dynamic approach for long-term strategies.

\section{REFERENCES}

[1] M. Appleyard, "How does knowledge flow? Interfirm patterns in the semiconductor industry”, Strategic Management Journal, 17(Winter), pp. 137-54, 1996.

[2] K. A. April, “Guidelines for developing a k-strategy”, Journal of Knowledge Management, 6(5), pp 445-456, 2002.

[3] J. Barney, "Firm resources and sustained competitive advantage", Journal of Management, 17(1), pp. 99-120, 1991.

[4] C.C. Baughn, J.S.R. Cao., L.T.M. Le, V.A. Lim, and K.E. Neupert, "Normative, social and cognitive predictors of entrepreneurial interest in China, Vietnam, and the Philippines", Journal of developmental entrepreneurship, vol 11 (1), pp 55-77, 2006.

[5] H. B. Bayyararapu, "Knowledge management strategies and firm performance", Published doctoral thesis, The University of Western Ontario London, Ontario, Canada, 2005.

[6] I.Becerra-Fernandez, and R. Sabherwal, "Organisational knowledge management: a contingency perspective", Journal of Management Information Systems, 18(1), 23-55, 2001.

[7] R. Bennet, and H. Gabriel, H. "Organisational factors and knowledge management within large marketing departments: an empirical study”, Journal of Knowledge Management, 3(3), pp. 212-225, 1999.

[8] M. Berrell, P. Wright and T.T.V. Hoa, "The influence of culture on managerial behavior” The Journal of Management, vol 18 (7), p 578, 1999.

[9] P. Bierly, and A. Chakrabarti, "Generic knowledge strategies in the US pharmaceutical industry”, Strategic Management Journal, 17(Winter), pp. 123-35, 1996.

[10] B. Choi, and H. Lee, "Knowledge management strategy and its link to knowledge creation process” Expert Systems with Applications, 23(3), pp. 173-187, 2002.

[11] B. Choi, and H. Lee, "An empirical investigation of knowledge management styles and their effect on corporate performance", Information and Management, 40, pp. 403-417, 2003.

[12] S.H. Chuang, "A resource-based perspective on knowledge management capability and competitive advantage: an empirical investigation”, Expert Systems with Applications, 27, pp. 459-465, 2004.

[13] E. Clemons, and M. Row, "Sustaining information technology advantage: the role of structural differences”, MIS Quarterly, 15(3), pp. 275-292, 1991.

[14] R. B. Cooper, and R. W. Zmud, "Information technology implementation research: a technological diffusion approach”, Management Science, 36(2), pp. 123-39, 1990.

[15] R. Deshpande, J.U. Farley, and D. Bowman, "Tigers, Dragons, and Others: Profiling high performance in Asian Firms”, Journal of international Marketing, vol 12 (3), pp 5-29, 2004.

[16] J. Egan, Rethinking construction: report of the construction task force on the scope for improving the quality and efficiency of UK construction, London: Department of the Environment, Transport, and the Regions, 1998.

[17] C. Egbu, J. Sturgesand, and B. Bates, "Learning from knowledge management and trans-organisational innovations in diverse project management environments”, in W. P Hughes, Ed. Proceedings of the 15th Annual Conference of the Associations of Researchers in Construction Management, Liverpool: Liverpool John Moores University, pp. 95-103, 1999. 
[18] R. G. Fichman, and C. F. Kemerer, "The assimilation of software process innovations: an organisational learning perspective”, Management Science 43(10), pp 1345-1363, 1997.

[19] A. O Gimenez, and M. Rincon, "Knowledge in the developing countries: an empirical approach in search of limitations and opportunities”, Proceedings of the Fourth European Conference on Knowledge Management, 18-19 September, Oxford, England, 2003.

[20] A. H. Gold, "Towards a theory of organisational knowledge management capabilities", Published doctoral thesis, University of North Carolina at Chaper Hill, USA, 2001.

[21] A. H. Gold, A. Malhotra, and A. H Segars, "Knowledge management: an organisational capabilities perspective', Journal of Management Information Systems, 18(1), pp. 185-214, 2001.

[22] R. M. Grant, “Toward a knowledge-based theory of the firm”, Strategic Management Journal, 17, pp. 109-22, 1996a.

[23] R. M Grant, "Prospering in dynamically-competitive environments: organisational capability as knowledge integration”, Organisation Science, 7(4), pp. 375-387, 1996b.

[24] V. Grove, and T. H. Davenport, "General perspective on knowledge management: fostering a research agenda”, Journal of Management Information Systems, 18(1), pp. 5-21, 2001.

[25] T.T. Ha, and F.W. Swierczek, "Motivation, entrepreneurship and the performance of SMEs in Vietnam", Journal of Enterprising Culture, vol 11(3): pp 47-68, 2003.

[26] J. F. Hair, R. E. Anderson, R. L. Tatham, and W. C. Black, Multivariate Data Analysis, $5^{\text {th }}$ Edition, Prentice-Hall: New Jersey, 1998.

[27] M. T Hansel, "The search-transfer problem: the role of weak ties in sharing knowledge across organisation subunits”, Administrative Science Quarterly, 44, pp. 82-111, 1999.

[28] H. D. Harlow, "The relationships between tacit and explicit knowledge management strategies and methodologies and firm financial and innovation outcomes" Published doctoral thesis, Alliant International University, USA, 2004.

[29] J. Henderson, and N. Venatraman, "Strategic alignment: leveraging information technology for transforming organisations”, IBM Systems Journal, 32, pp. 4-16, 1993.

[30] H. Y. Hsu, "Knowledge management and intellectual capital", Published doctoral thesis, Southern Illinois University at Carbondale, USA, 2006.

[31] S. E. Jackson, M. A. Hitt, and A. S. DeNisi, Managing knowledge for sustained competitive advantage: designing strategies for effective human resource management, Jossey-Bass, San Francisco, 2003.

[32] J. M. Kamara, G. Augenbroe, C. J. Anumba, and P. M. Carrillo, 'Knowledge management in the architecture, engineering and construction industry', Construction Innovation, 2, pp. 53-67, 2003.

[33] M. Khalifa, and V. Liu, V, "Knowledge management effectiveness", Proceedings of the Fourth European Conference on Knowledge Management, 18-19 September, Oxford, England, 2003.

[34] M. Khalifa, R. Lam, and M. Lee, 'An integrative framework for knowledge management effectiveness', Proceedings of the TwentySecond Conference on Information Systems, September, New Orleans, 2001.

[35] S. King-Kauanui, D.N. Su, and C. Ashley-Cotleur, "Impact of Human resource Management: SMEs performance in Vietnam”, Journal of developmental entrepreneurship, vol 11 (1), pp 79-95, 2006.

[36] C.T. Le, C. Rowley, Q. Truong, M. Warner, "To what extent can management practices be transferred between countries? The case of human resource management in Vietnam “, Journal of World Business vol 42: pp 113-127, 2007.

[37] D.D Le, Businessmen, business entrepreneurs and economic reform, Ho Chi Minh City: The Youth Publishing House, Saigon Economic Times, p.27, 2006.

[38] H. Lee, and B. Choi, B, "Knowledge management enablers, processes, and organisational performance: an integrative view and empirical examination”, Journal of Management Information Systems, 20(1), pp. 179-228, 2003.

[39] S. V. Lopez, "Competitive advantage and strategy formulation: The key role of dynamic capabilities”, Management Decision, 43(5), pp. 661669, 2005.

[40] M. Manovas, "Investigating the relationship between knowledge management capability and knowledge transfer success"s, Published Master of Science thesis, Concordia University, Canada, 2004.

[41] S. K. McEvily, and Chakravarthy, "The persistence of knowledgebased advantage: an empirical test for product performance and technological knowledge”, Strategic Management Journal, 23(4), pp. 285-305, 2002.

[42] M.W. Mcleod and N.T Dieu, Culture and customs of Vietnam, Westport, CT: Greenwood Press.

[43] M. M. Migdadi, "An integrative view and empirical examination of the relationships among knowledge management enablers, processes, and organisational performance in Australian enterprises”, Published doctoral thesis, University of Wollongong, Australia, 2005.

[44] D. Miller, "Knowledge inventories and managerial myopia", Strategic Management Journal, 23(8), pp. 689-706, 2002.

[45] J. Nahapiet, and S. Ghoshal, "Social capital, intellectual capital, and the organisational advantage”, Academy of Management Review, 23(2), pp. 242-66, 1998

[46] S. Narasimha, “Organisational knowledge, human resource management and sustained competitive advantage: toward a framework", Competitiveness Review, 10(1), pp. 123-135, 2000.

[47] S. Narasimha, "Salience of knowledge in a strategic theory of the firm", Journal of Intellectual Capital, 2(3), pp. 215-24, 2001.

[48] H. R. Nemati, "Global knowledge management: exploring a framework for research”, Journal of Global Information Technology Management, 5(3), pp. 1-10, 2002.

[49] T.H. Nguyen, Q. Alam, and M. Perry, "State versus Market: The paradox of Vietnam's experience with SME”', Proceeding of the $21^{\text {st }}$ Australian and New Zealand Academy of Management Conference, Sydney, Australia, 2007a.

[50] T.H. Nguyen, Q. Alam, "State and Market relationships: Public financial policy support for SMEs growth in Vietnam”, Proceeding of the Seventh International Business IBR conference, Sydney, Australia, 2007b.

[51] T.H. Pham, Creating good jobs by the support policies to develop SMEs, Hanoi: The National Political Publishing House, 2002.

[52] T. C. Powell, and A. Dent-Micallef, "Information technology as competitive advantage: the role of human" Strategic Management Journal, 18(5), pp. 375-405, 1997.

[53] A. Riahi-Belkaoui, "Intellectual capital and firm performance of US multinational firms”, Journal of Intellectual Capital, 4(2), pp 215-26, 2003.

[54] R. Sharkie, "Knowledge creation and its place in the development of sustainable competitive advantage”, Journal of Knowledge Management, 7(1), pp. 20-31,2003.

[55] T. A Smith, "Knowledge management and its capabilities linked to the business strategy for organisational effectiveness", Published doctoral thesis, Nova Southeastern University, USA, 2006.

[56] G. Szulanski, "Exploring internal stickiness: impediments to the transfer of best practice within the firm”, Strategic Management Journal, 17(Winter), pp. 27-43, 1996.

[57] D. J. Teece, G. Pisano, and A. Shuen, "Dynamic capabilities and strategic management”. Strategic Management Journal, 18(7), 509-533, 1997.

[58] V.V.Tuan, and N.K. Napier, "Paradoxes in Vietnam and America: Lessons earned”, Human resource planning, 23 (1): pp 7-8, (2): pp 910, (3): pp 8-10, 2000.

[59] G. Verona, and D. Ravasi, "Unbundling dynamic capabilities: an exploratory study of continuous product innovation”, Industrial and Corporate Change, 12(3), pp. 577-606, 2003.

[60] K. Y Wong, and E. Aspinwall, "An empirical study of the important factors for knowledge management adoption in the SME sector", Journal of Knowledge Management, 12(3), pp. 64-82, 2005.

[61] D. Zander, and B. Kogut, "Knowledge and the speed of the transfer and imitation of organisational capabilities: an empirical test”, Organisation Science, 6(1), pp. 76-92, 1995.

[62] W. Zheng, "The impact of organisational culture, structure, and strategy on knowledge management effectiveness and organisational effectiveness", Published doctoral thesis, University of Minnesota, USA, 2005.

[63] M. Zollo, and S. G. Winter, "Deliberate learning and the evolution of dynamic capabilities”, Organisation Science, 13(3), pp. 339-352, 2002. 